\title{
Influence of electric vehicles on the electrical grid
}

\author{
Leszek Kasprzyk ${ }^{1, *}$, Robert Pietracho ${ }^{1}$ \\ ${ }^{1}$ Poznan University of Technology, Institute of Electrical Engineering and Electronics, Piotrowo 3A, 60-965 Poznań, Poland
}

\begin{abstract}
The article discusses the issue of the development of electric energy storage and their impact on the power grid on the example of a charging station, to which a group of vehicles that have the capacity to transfer energy to the grid (V2G) is connected. An exemplary simulation of power distribution, energy losses in nodes of a standard IEEE 5 type network in two variants is presented: without and taking into account the impact of charging and discharging to grid the electric vehicles. The obtained results of power distribution in individual network nodes and power losses are presented in diagrams and commented.
\end{abstract}

\section{Introduction}

In recent years, one can notice the dynamic development of various types of energy storage, as well as systems powered from them, among which electric vehicles should be distinguished [1-5]. Although such vehicles are not designed to transfer energy to the grid, but due to the fact that many vehicles are used for 1-2 hours a day, and their energy storages are characterized by power of hundreds $\mathrm{kW}$ and energy capability of the order of hundreds $\mathrm{kWh}$, they can be used as an intervention source of energy for the power system [6-8]. Currently, their number is not large, but it is expected that in the coming years the number of electric vehicles will increase. This will make real possibility of using V2G technology (vehicle to grid) and that makes a significant impact on the operation of the power grid [9-11]. The impact of a large number of vehicles can have two consequences - during charging it can cause excessive overload (reduction of voltage and transfer losses), but simultaneously supervised charging processes and possible discharge to the network can support the system (eliminate excessive voltage drops and power losses) [12-15]. Therefore, the selection of the optimal configuration of this type of structures requires advanced analysis as well as many technical aspects, and sometimes multi-aspect optimization. [16-25]. For this reason, in this work the analysis of the impact of charging and discharging a group of electric vehicles on the power grid was analyzed.

\section{Example}

As an example, a power flow analysis was carried out in the standard IEEE 5 type network with voltage level equal $20 \mathrm{kV}$ for two cases: no electric vehicles and electric vehicles that act as energy storage, transferring energy to the grid. A daily electricity demand profile has been assumed for selected network nodes, which is shown in fig. 1. In the fig. 2, the network load in individual nodes is shown, including 4 groups of electric vehicles with different charging and discharging profiles. The values of generated power in individual nodes are: $\mathrm{P}_{\mathrm{N} 2}=5 \mathrm{MW}, \mathrm{P}_{\mathrm{N} 3}=7 \mathrm{MW}, \mathrm{P}_{\mathrm{N} 4}=5 \mathrm{MW}, \mathrm{P}_{\mathrm{N} 5}=8 \mathrm{MW}$.

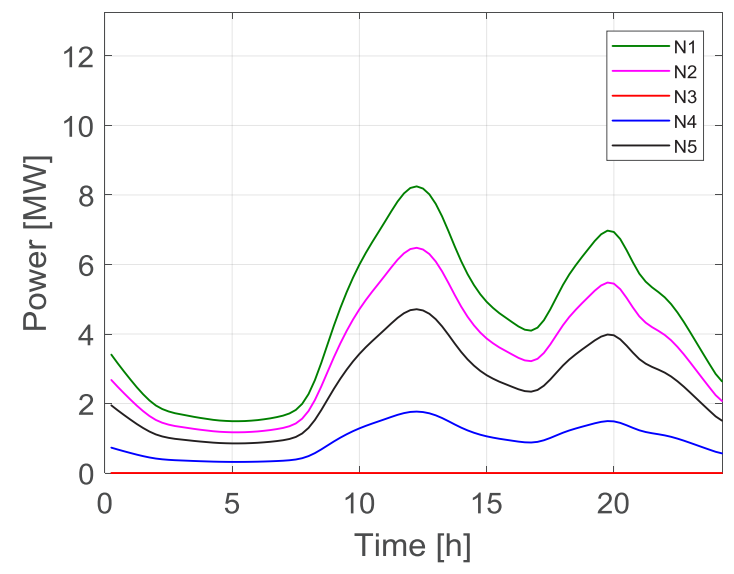

Fig. 1. Grid load characteristics without electric vehicles.

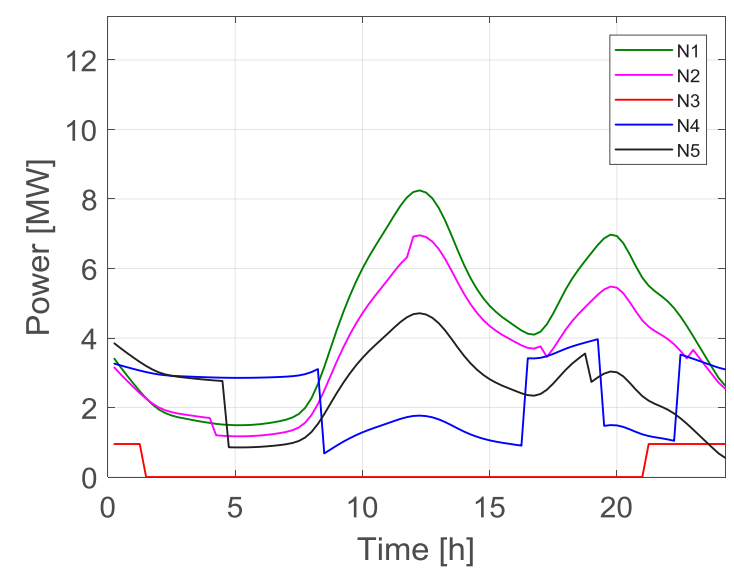

Fig. 2. Grid load characteristics with electric vehicles. 
The fig. 3 and fig 4 show the total power and energy losses for all transmission lines in the examined case. It can be seen that the losses resulting from the incorrect generation match to the loads have been reduced using the power of the batteries of electric vehicles.

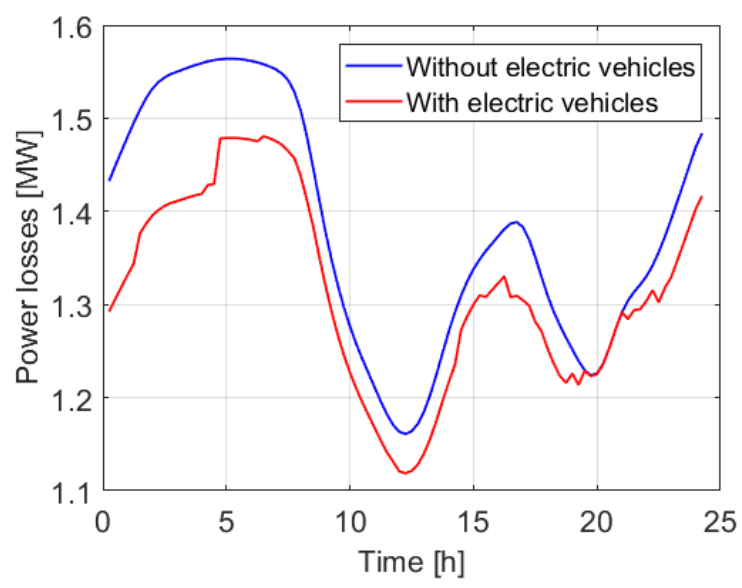

Fig. 3. Comparison of total power losses in the lines under consideration, without and with electric vehicles.

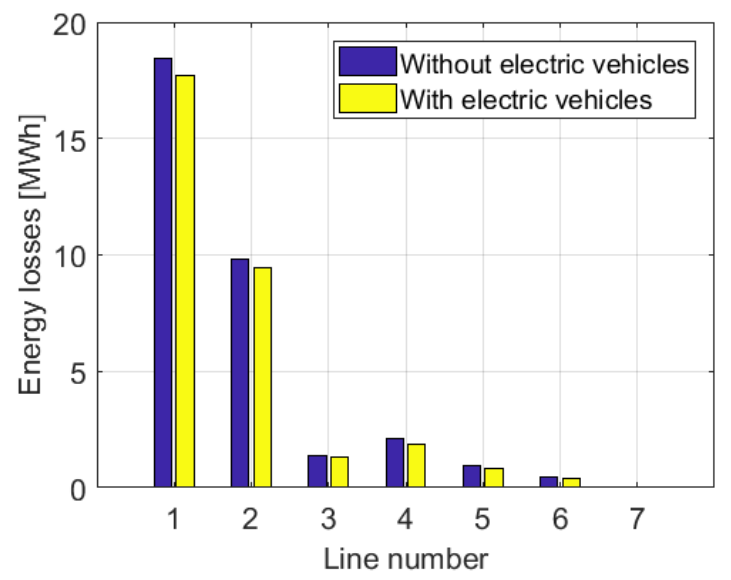

Fig. 4. Daily energy losses in the grid under consideration.

\section{Conclusion}

The simulation shows that electric vehicles can be used as additional energy storage and take part in regulatory processes of the power system. This regulation is based on local coverage of system losses due to load change at network nodes. In the case of using vehicles as intervention sources, one should also take into account the economic aspects of this solution, i.e. the impact of cyclic discharges on battery life and modernization of existing substations especially on the medium level to technology that would allow efficiently regulate energy flow to and from vehicles.

\section{References}

1. L. Kasprzyk, Eksploat. Niezawodn. 19/2, 229-236 (2017)
2. D. Burzyński, L. Kasprzyk, E3S Web of Conferences, 14, 01041 (2017)

3. S Balischewski, I Hauer, M Wolter, C Wenge, P. Lombardi, P Komarnicki, ISGT-Europe, IEEE PES, $1-6(2017)$

4. L. Kasprzyk, K. Bednarek, Prz. Elektrotech. 91/12, 129-132 (2015)

5. B. Ohde, G. Ślaski, International Automotive Conference (Materials Science and Engineering) 148, 012027 (2016)

6. J. Jajczyk, A. Dobrzycki, M. Filipiak, D. Kurz, E3S Web of Conferences, 19, 01027 (2017)

7. D. Głuchy, L. Kasprzyk, Prz. Elektrotech. 93/12, 99-102 (2017)

8. P. Komarnicki, P. Lombardi, Z. Styczynski, Electric Energy Storage Systems: Flexibility Options for Smart Grids, (Springer, 2017)

9. J. Alemany, P. Komarnicki, J. Lin, F. Magnago, Electr. Power Syst. Res. 140, 363-377 (2016)

10. J. Alemany, F. Magnago, P. Lombardi, B. Arendarski, P. Komarnicki, Math. Probl. Eng., 1876934 (2017)

11. J. M. Alemany, L. Kasprzyk, M. Fernando, Electr. Power Syst. Res. 160, 429-438 (2018)

12. L. Kasprzyk, A. Tomczewski, K. Bednarek, Prz. Elektrotech. 87/12b, 82-85 (2011)

13. W. Opydo. A. Dobrzycki, Electr. Eng. 94/1, 37-48 (2012)

14. J. M. Alemany, F. Magnago, D. Moitre, IEEE Latin Am. Trans. 11/1, 421-425 (2013)

15. K. Bednarek, L. Kasprzyk, Prz. Elektrotech. 88/12b, 236-239 (2012)

16. K. Bednarek, R. Nawrowski, A. Tomczewski, Prz. Elektrotech. 84/1, 62-64 (2008)

17. L. Kasprzyk, Prz. Elektrotech. 88/7B, 131-133 (2012)

18. Tomczewski, Sci. World J., 643769 (2014)

19. L. Kasprzyk, Prz. Elektrotech. 83/12, 128-131 (2007)

20. D. Głuchy, D. Kurz, G. Trzmiel, Prz. Elektrotech. 89/6, 78-80 (2013)

21. K. Skowronek, G. Trzmiel, Prz. Elektrotech. 83/11, 108-110 (2007)

22. L. Kasprzyk, R. Nawrowski, A. Tomczewski, Studies in Computational Intelligence 119, 21-29 (2008)

23. G. Trzmiel, Eksploat. Niezawodn. 19/4, 516-521 (2017)

24. D. Kurz, Intern. Confer. Computational Problems of Electrical Engineering, 1-5 (2016)

25. L. Kasprzyk, K. Bednarek, Prz. Elektrotech. 85/12, 65-68 (2009) 